\title{
A REPRESENTAÇÃO TEMÁTICA DAS XILOGRAVURAS DO MUSEU DE ARTE DE LONDRINA: UMA ANÁLISE DA COLEÇÃO PAULO MENTEN
}

\author{
(1) Viviane Faria Machado \\ Mestrando Universidade Estadual de Londrina, Paraná \\ vfmacfar@gmail.com
}

\section{RESUMO}

A pesquisa tem por finalidade analisar como são representadas tematicamente as xilogravuras da coleção Paulo Menten inseridas no acervo do Museu de Arte de Londrina e identificar os termos indexados no sistema InfoMusa. As xilogravuras constituem-se de técnicas específicas tornando-as importantes no conjunto entre história, arte e impressão utilitária. Para que este tipo de obra possa ser recuperada em uma unidade de informação é necessário que passe por um tratamento da informação visando a sua organização e representação do conteúdo documental, campo de estudo da área da Organização da Informação. Neste sentido as obras xilográficas precisam de tratamento temático, pois as xilogravuras são fontes de informação que retratam uma época e seu contexto. Sendo assim, a metodologia proposta foi de análise de conteúdo de forma a averiguar como são feitas as representações das xilogravuras, e relacionando-as de acordo com as categorias previamente estabelecidas no estudo, visando a organização e representação da melhor forma possível. Sendo que os resultados obtidos demonstram uma insuficiência no que se refere aos termos descritores de indexação, impossibilitando a facilidade dos pesquisadores de recuperar estes documentos, pois não atinge o nível de exaustividade e nem especificidade quanto as dimensões precisas para indexar documentos.

Palavras-chave: Xilogravura. Tratamento Temático de Imagens. Indexação de Imagens. Paulo Menten.

\section{INTRODUÇÃO}

A pesquisa se objetivou em analisar as representações temáticas das xilogravuras do Museu de Arte de Londrina (MAL) considerando o contexto histórico, a função utilitária, e a produção artística. Ao qual foram perpassados por processos de identificação das representações xilográficas da coleção Paulo Menten, necessitando do levantamento dos termos de indexação contidos no InfoMusa e na ficha manual, e também, na verificação se os termos levantados constituem-se numa estruturação que visa preencher as categorias previamente estabelecidas.

Para a aplicação da pesquisa utilizou-se como metodologia a Análise de Conteúdo, método de investigação formulada por Laurence Bardin (2004). Ao qual para constituir o corpus da análise baseou-se em uma escolha aleatória perante a observação de 30 xilogravuras, e das informações disponíveis no sistema InfoMusa e na ficha manual.

Sendo assim, esta pesquisa é importante pela abordagem do tratamento temático das xilogravuras que é ainda escassa, proporcionando um campo a ser explorado devido ao 


\section{SEMINÁRIO DE PESQUISA EM CIÊNCIAS HUMANAS - SEPECH \\ Humanidades, Estado e desafios didático-científicos \\ Londrina, 27 a 29 de julho de 2016}

seu longo processo da construção na história. E assim, este trabalho pretende trazer contribuições ao tratamento das obras xilográficas para que sejam recuperadas no momento da busca.

\section{REPRESENTAÇÃO TEMÁTICA DE IMAGENS}

Para que possa haver uma transmissão da informação é necessário que haja um tratamento adequado da informação, pois ao se representar uma imagem é preciso realizar a transcodificação e a interpretação. Entende-se por transcodificação, como a tradução de um código para outro, pois analisar uma imagem significa, 'traduzir' determinados elementos de um código icônico para um código verbal (SMIT, 1987). A transcodificação gera condições para o processo de interpretação da imagem.

Ao descrever uma imagem não se pode errar por omissão, ao qual esta análise deve responder algumas questões para atender as necessidades específicas, aos quais estão elencadas abaixo (SMIT, 1987):

a) COMO: Questões técnicas da produção da imagem;

b) ONDE (ambiente): Localização da imagem no espaço, a descrição do lugar;

c) QUANDO: Localização da imagem no tempo (tempo histórico, atual, época do ano);

d) QUEM: Quando possui imagem de seres vivos (descrição precisa dos seres vivos);

e) O QUE: Descrição das ações dos seres vivos (descrever a função daquilo que a imagem representa);

f) ONDE (espaço): Descrição do ambiente em que se encontram os seres vivos (elemento natural ou artefato, caso não haja seres vivos este já foram respondido no item b, localização no espaço).

Quando se representa uma imagem verifica-se que existem duas possibilidades, sendo um referente genérico e um referente específico, em que Manini (2001) exemplifica que o referente genérico identifica a imagem e descreve de forma generalizada, e o referente específico reconhece a imagem através de uma legenda ou do próprio repertório do indexador.

As funções que a imagem pode evocar como meio de categorização são abordadas por Camargo (2011) no qual destaca que a imagem se configura a três funções, que são: a função simbólica, a função documental e a função poética. Fazendo uma relação com as categorias elencadas nesta pesquisa, pode-se definir da seguinte maneira:

- Função Utilitária: equivale-se a função simbólica, em que se tem a imagem instrumento do contexto social;

- Função Contexto Histórico: considera-se como uma função documental, pois permite a imagem se tornar um registro do passado, de diferentes épocas e civilizações;

- Função de Produção Artística: configura-se como uma função poética, no qual se expressa à imagem como arte, procurando-se manifestar o valor estético da obra.

Para que se possam representar as informações dispostas no documento, o tratamento temático se constitui de vários instrumentos que, de acordo com Dias e Naves (2013) os processos do tratamento temático da informação são a classificação, a catalogação por assunto e a indexação, porém o foco desta pesquisa está na indexação. 


\section{SEMINÁRIO DE PESQUISA EM CIÊNCIAS HUMANAS - SEPECH \\ Humanidades, Estado e desafios didático-científicos \\ Londrina, 27 a 29 de julho de 2016}

\subsection{Aspectos Essências para a Indexação}

A indexação segundo a Associação Brasileira de Normas Técnicas - NBR 12676 (1992, p. 2), indexação é o "ato de identificar e descrever o conteúdo de um documento com termos representativos dos seus assuntos e que constituem uma linguagem de indexação". Entende-se, portanto, que a indexação é um processo do tratamento temático da informação, que visa representar os assuntos abordados pelo documento para que este possa ser recuperado. Para que isso aconteça a indexação distingue-se em duas etapas: a análise conceitual e a tradução (LANCASTER, 2004)

A primeira etapa contempla a análise de assunto, que é o processo de identificação dos assuntos dispostos no documento (LANCASTER, 2004). Quanto à segunda etapa de tradução, consiste na conversão do conteúdo documental em um conjunto de termos pré-estabelecido pelo indexador (LANCASTER, 2004), pode-se entender que é a decisão de quais termos devem ser adotados para representar o assunto do documento.

$\mathrm{O}$ processo de indexar precisa obedecer aos princípios de exaustividade e especificidade, que são critérios adotados pelos indexadores no momento da seleção dos conceitos. A exaustividade são termos atribuídos como descritores do conteúdo informacional, pois quanto mais termos for atribuído, mais termos a indexação vai empregar (RUBI, 2009).

Na dimensão da especificidade a norma NBR 12676 (1992, p. 3) se refere "[...] ao grau de precisão com que um termo define determinado conceito do documento", quanto mais específico for o termo indexado melhor será a sua recuperação. E, também, a indexação precisa atender aos princípios de revocação e relevância, ao qual Dias e Naves (2013) consideram que a revocação se refere a quantidade de documentos recuperados e que condiz com a capacidade de relevância nos documentos recuperados pelo usuário. Portanto, para a realização de uma indexação de obras imagéticas deve-se atentar para o tipo de obra analisada, e conhecer os aspectos técnicos e seu contexto histórico.

\section{ASPECTOS TÉCNICOS E HISTÓRICO DAS XILOGRAVURAS}

A técnica xilográfica é o método de transferência de uma imagem gravada em uma matriz de madeira para outro tipo de suporte, ou seja, a madeira é esculpida ou talhada pelo gravador formando-se uma imagem para que seja impressa, em que a xilografia é a técnica de gravar num suporte de madeira, e a xilogravura é a impressão, sendo assim, é o produto fim da técnica (COSTELLA,1984).

Há duas formas para serem feitas as matrizes, sendo a xilografia ao fio, e a xilografia de topo. De acordo com Tavares $(2005$, p. 23$)$ " [...] na xilografia ao fio, a imagem é produzida num pedaço de madeira cujo corte fez paralela as fibras [...]", já a na xilografia de topo "[...] o pedaço da madeira é obtido com um corte transversal ao tronco, deixando as fibras alinhadas perpendicularmente ao corte da serra [...]" (TAVARES, 2005, p. 23).

Perante a conceituação histórica das obras xilográficas, elas surgem com a impressão feita em panos no Egito e China (COSTELLA, 1984). Já na Europa “[...] as primeiras impressões xilográficas tenham sido feitas a partir do século sexto, com a função de estampar tecidos”, e a impressão em papel “[...] séculos quatorze e quinze, 


\section{SEMINÁRIO DE PESQUISA EM CIÊNCIAS HUMANAS - SEPECH \\ Humanidades, Estado e desafios didático-científicos \\ Londrina, 27 a 29 de julho de 2016}

quando começaram a ser produzidas, em grande número, xilogravuras de imagens sacras e de cartas de baralho" (COSTELLA, 2003, p.12).

Após o aparecimento da tipografia deixou de usar a xilografia para a produção de texto e ficando apenas com a impressão de imagens, conforme Costella (1984, p. 44) descreve que as duas técnicas eram impressão em relevo, usavam a mesma tinta, tendo os blocos de madeira e de metal da mesma altura, sendo usadas simultaneamente na impressão.

Como produção utilitária se emprega na impressão em jornais, revistas, livros, isto é, passa a ser usada para fins comerciais, principalmente no início da veiculação dos periódicos (FERREIRA, 1976), isso mostra como esta arte possibilitou imagens nesses meios de comunicação, em que não apenas se apresentava letras para as pessoas. Outra relevância desta técnica é na construção da gravura nas capas dos folhetos de cordel, em que a xilogravura se desenvolveu tanto no campo utilitário, quanto no campo artístico.

\subsection{As Obras Xilográficas de Paulo Menten}

Dentro do panorama artístico que constitui a cidade de Londrina, uma das coleções mais importante que compõem o acervo do Museu de Arte é a da coleção Paulo Menten. O artista plástico nasceu em 1927, na cidade de São Paulo, aprendeu a arte da gravura com Lívio Abramo, artista gravador de grande prestígio no país (SILVA, 2012). Mudou-se para Londrina na década de 80, produziu muitas gravuras com diversas temáticas, além de preocupar-se com o ensinamento de gravura para a população local, falecendo em 2011 aos 83 anos (SILVA, 2012).

Sendo seu legado inestimável para a cidade, o artista realizou 15 gravuras para a Coleção do Memorial do Pioneiro, que estão localizadas em frente à Concha Acústica, homenageando os colonizadores de Londrina (LEMES, 2006). Seu trabalho artístico na xilogravura é apurado, transmite com nitidez a temática da obra, conforme exposto abaixo (SIMONETTI, 2006):

- Cenas sociais Representam as tragédias das histórias sociais do Brasil, dentre elas a chacina da Candelária e a mineração da Serra Pelada;

- Cultura Nordestina Imaginário popular nordestino se mistura com a realidade, representando seres místicos e as fantasias populares;

- Corpo Feminino Silhuetas corpulentas do corpo feminino explorando a sensualidade natural;

- Mulher-dama Retrata a figura da prostituta como símbolo mitológico assumindo o amor carnal;

- Fachadas coloniais Representatividade das fachadas coloniais em formatos geométricos;

- Londrina - Paisagem urbana Retrata paisagens urbanas da cidade de Londrina;

- Pioneiros de Londrina Retrata os pioneiros da cidade de Londrina.

Percebe-se que o artista Paulo Menten cria categorias representativas em suas obras, sendo que esses elementos riquíssimos devem evidenciar-se em uma indexação. 


\section{SEMINÁRIO DE PESQUISA EM CIÊNCIAS HUMANAS - SEPECH \\ Humanidades, Estado e desafios didático-científicos \\ Londrina, 27 a 29 de julho de 2016}

\section{ANÁLISE E DISCUSSÃo DOS RESULTADOS}

A análise da pesquisa se consagrou pelas fases de: pré-análise, em que se estabeleceu o primeiro contato com as xilogravuras de Paulo Menten no Museu de Arte de Londrina (MAL); a exploração do material, que foram construídas grelhas de analisar dos dados, sendo estas alimentadas por elementos previamente observados com a inferência das categorias estabelecidas.

E por ultimo a fase de tratamento dos resultados, que analisou os elementos coletados no sistema InfoMusa verificando os critérios adotados pelo MAL. Elaborando sínteses dos dados explorados com o levantamento teórico. Para a designação da temática das xilogravuras, optou-se em usar as temáticas do artista Paulo Menten em suas obras.

\subsection{Xilogravura: Paisagem Urbana}

O corpus do documento explorado abaixo apresenta as imagens derivadas do print da interface do InfoMusa, e da imagem da xilogravura.

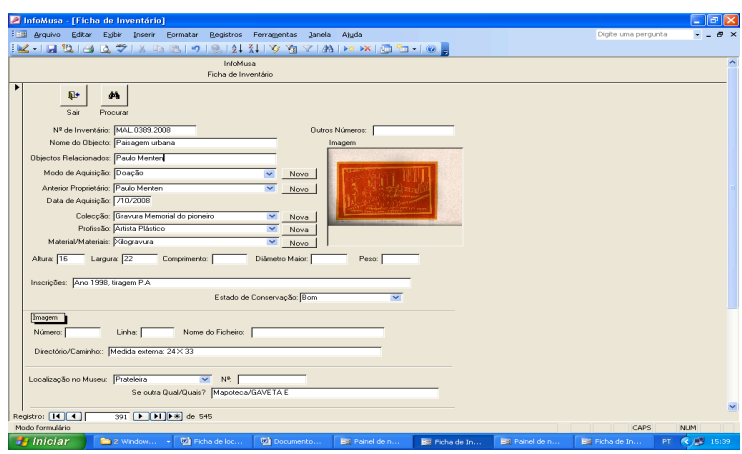

Figura 1 - Interface InfoMusa - Paisagem Urbana

Fonte: LONDRINA. Museu de Arte de Londrina (2014)

A figura 1 corresponde a interface do InfoMusa. Compondo a estruturação da grade exposta no quadro 1.

\begin{tabular}{|c|c|c|c|}
\hline \multirow[b]{2}{*}{ Elementos } & \multicolumn{3}{|l|}{ CATEGORIAS } \\
\hline & $\begin{array}{l}\text { Contexto } \\
\text { Histórico } \\
\end{array}$ & Produção Artística & Função Utilitária \\
\hline Ano Produção & 1998 & & \\
\hline Título da Obra & & Paisagem urbana & \\
\hline Coleção ou Série & $\begin{array}{l}\text { Gravura } \\
\text { Memorial do } \\
\text { Pioneiro }\end{array}$ & & \\
\hline $\begin{array}{l}\text { Informação do } \\
\text { Contexto da Obra }\end{array}$ & & & $\begin{array}{lr}\text { Obra utilizada no } \\
\text { Memorial } & \text { do } \\
\text { Pioneiro da Praça } 1^{\circ} \\
\text { de Maio da cidade } \\
\text { de Londrina }\end{array}$ \\
\hline
\end{tabular}




\section{SEMINÁRIO DE PESQUISA EM CIÊNCIAS HUMANAS - SEPECH \\ Humanidades, Estado e desafios didático-científicos \\ Londrina, 27 a 29 de julho de 2016}

\begin{tabular}{|l|l|l|l|}
\hline $\begin{array}{l}\text { Termo de } \\
\text { Indexação }\end{array}$ & Não possui \\
\hline & & $\begin{array}{l}6 \\
\text { masculinos personagens } \\
\text { com chapéu e um na } \\
\text { porta em meio corpo } \\
\text { longitudinal. Fachada } \\
\text { Descrição da Obra }\end{array}$ & $\begin{array}{l}\text { com 4 portas tipo } \\
\text { comercial }\end{array}$ \\
\hline Técnica da Obra & & Xilogravura & \\
\hline Temática da Obra & Não descreve & \\
\hline
\end{tabular}

Quadro 1 - Grelha de análise InfoMusa e ficha manual - Paisagem Urbana

Fonte: Elaborado pela autora (2014)

A representação da obra feita por data de produção, título, coleção ou série, são informações referente ao contexto, a descrição do conteúdo, e a técnica da obra. Que são elementos essenciais para a leitura do documento, porém não se aplica neste sistema relações de termos temáticos, que poderiam contribuir de maneira significativa para a recuperação da obra.

Os termos atribuídos podem trazer informações significativas para representar o documento (CARDOSO FILHO; SANTOS, 2012), pois às vezes o título e a coleção não conseguem contemplar o assunto tratado na imagem, por isso verifica-se a necessidade de representar o documento com a temática disposta pelo artista, uma vez que este já realizou a segmentação da obra.

As categorias estão relacionadas com as informações do sistema do museu em que pertence ao contexto histórico, contendo informações nos itens de ano de produção e a coleção da obra, referindo-se a função de registro do passado. Ao que se refere à produção artística são elencados o título, o resumo e a técnica, configura-se como forma de expressão da arte. E no campo utilitário está designado o contexto da obra, devido a obra ser produzida para atingir um objetivo, criar o memorial dos pioneiros de Londrina.

Quanto a indexação percebe-se que o InfoMusa e a ficha manual não contemplam uma exaustividade, pois insere apenas em sua base de dados informações que correspondem ao ano de produção da obra, o título da obra, a coleção ou série que a obra pertence, informações do contexto ao qual a obra foi inserida no museu, e a descrição da imagem da obra. Verifica-se que estes dados dariam informações suficientes para construir termos padronizados para a indexação das xilogravuras, atendendo, assim, a necessidade da busca informacional pelo usuário/ pesquisador.

No nível de especificidade, consideram-se os termos atribuídos que mais se aproxima da temática do documento, em que, “[...] aumenta a precisão na recuperação da informação, uma vez que leva em consideração a intensidade de um termo em relação ao conteúdo de um documento" (CARDOSO FILHO; SANTOS, 2012, p. 189). Para atender a especificidade percebe-se que a temática exposta pelo próprio artista Paulo Menten atenderia de forma eficiente a questão levantada.

Segue-se a imagem da xilogravura retratada na figura 3, e a grade de análise feita sobre a imagem xilográfica representada no quadro 2 , ao qual realizou-se a análise em da própria xilogravura, em que a coleta dos dados foram retirados da obra, sem intervenção de outra fonte de informação. 


\section{SEMINÁRIO DE PESQUISA EM CIÊNCIAS HUMANAS - SEPECH \\ Humanidades, Estado e desafios didático-científicos \\ Londrina, 27 a 29 de julho de 2016}

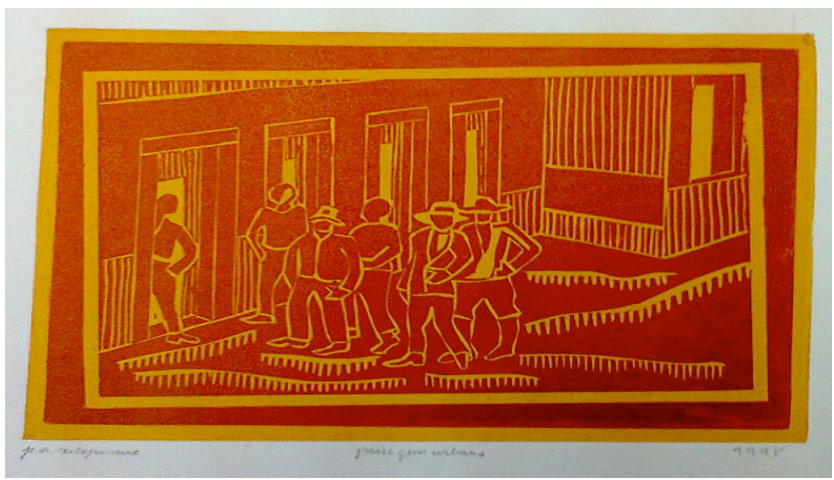

Figura 3 - Imagem xilogravura Paisagem Urbana

Fonte: Menten (1998)

\begin{tabular}{|c|c|c|c|}
\hline \multirow{2}{*}{ Elementos } & \multicolumn{3}{|l|}{ CATEGORIAS } \\
\hline & Contexto Histórico & Produção Artística & Função Utilitária \\
\hline Ano da Obra & 1998 & & \\
\hline Título da Obra & \multicolumn{3}{|l|}{ Paisagem Urbana } \\
\hline Série ou Coleção & \multicolumn{3}{|l|}{ Paisagem urbana } \\
\hline $\begin{array}{l}\text { Descrição do } \\
\text { Conteúdo da Obra }\end{array}$ & \multicolumn{3}{|c|}{$\begin{array}{l}\text { Imagem representa } 6 \text { figuras masculinas em pé, } 3 \text { usando chapéu, } \\
1 \text { figura aparecendo metade do corpo na vertical e a outra metade } \\
\text { escondida atrás da entrada da porta da edificação. Fachada com } 4 \\
\text { portas e uma janela }\end{array}$} \\
\hline Tipo de Técnica & & Xilogravura ao fio & \\
\hline Temática da Obra & \multicolumn{3}{|c|}{$\begin{array}{l}\text { Londrina - Paisagem urbana } \\
\text { Pioneiros de Londrina }\end{array}$} \\
\hline
\end{tabular}

Quadro 2 - Grelha de análise referente à xilogravura Paisagem Urbana

Fonte: Elaborado pela autora (2014)

A obra constitui nas três categorias em que na produção artística, estão os itens de título, série ou coleção, descrição do conteúdo, tipo de técnica e temática, sendo conforme Costella (1984, p. 34) "Quando o inventor é o próprio artista, as invenções nascem utilitárias. Depois o artista se achega, observa, experimenta e, qual um mágico, faz saltar de sua cartola um belo e surpreendente fruto da imaginação".

Já o que corresponde a função utilitária, enquadra-se os itens título, série ou coleção descrição do conteúdo e temática, pois o artista criou a obra para atender a determinado fim, por isso, que estes elementos precisam ser considerados no campo de utilidade, em que se destaca a paisagem urbana de uma região.

Quando evoca a função de contexto histórico, os itens correspondentes são o ano de produção da obra, o título, a série ou coleção, a descrição do conteúdo e a temática, de acordo com Camargo $(2011$, p. 209) a função de contexto histórico da imagem "[...] é a capacidade de atuar como testemunha ocular do seu contexto existencial. O ser humano, ao realizar imagens de seu meio, também traduziu seus anseios, seu cotidiano, suas esperanças e, assim, nos legou um precioso registro social e antropológico de sua existência".

Para a descrição das imagens escolheu os critérios selecionados por Smit (1987) respondendo as questões ONDE, configura-se a descrição do lugar descrevendo a 


\section{SEMINÁRIO DE PESQUISA EM CIÊNCIAS HUMANAS - SEPECH \\ Humanidades, Estado e desafios didático-científicos \\ Londrina, 27 a 29 de julho de 2016}

localização da imagem no espaço. Atende, também, como critérios para a descrição da imagem os elementos QUEM, sendo a descrição dos seres, O QUE, corresponde a ação efetuado por esses seres, e por último, ONDE, o ambiente em que estão retratados estes seres. Constituindo, assim, um resumo no nível mínimo.

A temática conceituada em torno dos termos adotados por Paulo Menten, as quais são: Londrina - paisagens urbanas, retratando a paisagem urbana de Londrina; e Pioneiros de Londrina, sendo representados os pioneiros da cidade de Londrina com imagens "[...] das casas de madeira, dando início a construção de Londrina" e também "[...] vai buscar as origens da cidade e, a partir de fotos antigas, resgata a história dos pioneiros de Londrina" (SIMONETTI, 2006, p. 14).

Pode-se verificar que as informações contemplam as categorias, que já foram levantadas neste estudo. $\mathrm{O}$ que remete a xilogravura como uma técnica que permite se estabelecer significados que atuam no campo utilitário, no artístico e como registro do tempo.

\section{CONSIDERAÇÕES FINAIS}

O presente trabalho conseguiu expor alguns elementos referentes à representação temática da informação sobre os documentos xilográficos, em que se observou que as xilogravuras correspondem aos níveis das três categorias: de contexto histórico; sobre a função utilitária; e quanto à produção artística, e suas formas de expressão e reflexão dos artistas. Possibilitando levantar indagações sobre as formas de organizações e representações destes recursos imagéticos.

Sendo assim, compreende-se que podem ser realizadas pesquisas posteriores com as xilogravuras em relação à organização e representação do conhecimento e da informação. Percebe-se que a análise de imagens possui peculiaridades, ao qual precisam de estudos prévios para sua elaboração, visto que a singularidade das técnicas, o público a que se destina e as proposições dos autores permeiam todo o processo de entendimento das obras que influenciarão diretamente na disponibilização e na recuperação destas informações. Por isso o estudo ainda tem muitos campos para se explorar.

\section{REFERÊNCIAS}

ASSOCIAÇÃO BRASILEIRA DE NORMAS TÉCNICAS. NBR12676. Métodos para a análise de documentos - determinação de seus assuntos e seleção de termos de indexação. Rio de Janeiro, 1992.

BARDIN, L. Análise de conteúdo. 3.ed. Lisboa/Portugal: Edições 70, 2004.

CAMARGO, I. A. Imagem: representação versus significação. In: GAWRYSZEWSKI, A. (Org.). Imagem em debate. Londrina: Eduel, 2011.

CARDOSO FILHO, J. C.; SANTOS, M. M. Processos e temas selecionados. In: ALVARES, L. (Org.). Organização da informação e do conhecimento: conceitos, subsídios interdisciplinares e aplicações. São Paulo: B4 Ed., 2012. Cap. 4. 


\section{SEMINÁRIO DE PESQUISA EM CIÊNCIAS HUMANAS - SEPECH \\ Humanidades, Estado e desafios didático-científicos \\ Londrina, 27 a 29 de julho de 2016}

COSTELlA, A. Breve história ilustrada da xilogravura. Campos do Jordão: Mantiqueira, 2003.

Mantiqueira, 1984.

Introdução à gravura e história da xilografia. Campos do Jordão:

DIAS, E. W.; NAVES, M. M. L. Análise de assunto: teoria e prática. 2. ed. rev. Brasília: Briquet de Lemos, 2013.

FERREIRA, O. C. Imagem e letra: introdução à bibliologia brasileira: a imagem gravada. São Paulo: Universidade de São Paulo, c1976. 278 p.: il.

LANCASTER, F. W. Indexação e resumos: teoria e prática. 2. ed. rev. e atual. Brasília: Briquet de Lemos, 2004.

LEMES, F. O 'pai' dos totens do memorial. Folha de Londrina, Londrina, 22 agosto 2006. Folha 2. P. 2.

LONDRINA. Secretaria de Cultura de Londrina. Museu de Arte de Londrina. Base de dados Infomusa. Londrina, 2014.Print.

LONDRINA. Secretaria de Cultura de Londrina. Museu de Arte de Londrina. Ficha Manual. Londrina, 2014. Foto.

MANINI, M. P. Análise documentária de imagens. Informação \& Sociedade: estudos, Paraíba, v. 11, n. 1, 2001. Disponível em: $<$ http://periodicos.ufpb.br/ojs/index.php/ies/article/viewFile/313/236>. Acesso em 06 set. 2014.

MENTEN, P. Paisagem urbana. 1998. 1 gravura. Museu de Arte de Londrina.

RUBI, M. P. Os princípios da política de indexação na análise de assunto para catalogação: especificidade, exaustividade, revocação e precisão na perspectiva dos catalogadores e usuários. In: FUJITA, M. S. L. (Org.). A indexação de livros: a percepção de catalogadores e usuários de bibliotecas universitárias: um estudo de observação do contexto sociocognitivo com protocolos verbais. São Paulo: Cultura Acadêmica, 2009. 154 p. Capítulo 4.

SILVA, L. C. Gravura em Londrina: Paulo Menten. In: CONGRESSO INTERNACIONAL DE MUSEOLOGIA, 2., 2012, Maringá. Anais... Maringá: Universidade Estadual de Maringá, 2012. p. 1-8.

SIMONETTI, J. Poiesis: Paulo Menten. Londrina: Edições Humanidades, 2006.

SMIT, J. W. Análise de imagem: um primeiro plano. In: (Coord.). Análise documentária: a análise da síntese. 2. ed. Brasília: IBICT, 1987. Cap. 6. 


\section{SEMINÁRIO DE PESQUISA EM CIÊNCIAS HUMANAS - SEPECH \\ Humanidades, Estado e desafios didático-científicos}

Londrina, 27 a 29 de julho de 2016

TAVARES, L. A. A imagem impressa e ciência: ilustrações em livros didáticos de física: séculos XIX e XX. São Paulo, 2005. 93f. Dissertação (Mestrado em História da Ciência) - Pontifícia Universidade Católica, São Paulo, 2005. 